\title{
The Effect of the Health Personnel Exposed to the Attack of Patients and Relatives on the Perception of Aggression
}

\author{
Mahmut Kilic*
}

Yozgat Bozok University, Faculty of Medicine, Department of Public Health, Yozgat, Turkey

\begin{abstract}
Purpose: The aim of the study is to evaluate the effect of health personnel's exposure to the violence of patients and relatives on the perception of aggression.

Materials and Methods: This cross-sectional study was conducted in 2015 among health personnel who are in contact with patients and their relatives working in health institutions in Yozgat city center. The study was completed with 358 people who agreed to participate in the study with verbal consent. The data were collected through the Perception of Aggression Scale (POAS), the socio-demographic form and a form that evaluates the health personnel being attacked. In the analysis of the data, univariate tests and multivariate regression analyzes were used.

Results: Of the health personnel, $81.6 \%$ of them stated that they were exposed to the violence of the patients and their relatives during their professional career and $37.7 \%$ during the last 12 months. In the regression analysis, the perception of functional aggression was higher in those working in university hospitals, and lower in physicians $(p<0.05)$. Dysfunctional aggression perception was lower in medical secretaries, family health center staff, and university hospital staff $(p<0.05)$. No significant relationship was found between the perception of aggression and age, gender, education level, professional experience (years), and their exposure to attack during the past 12 months $(p>0.05)$.
\end{abstract}

Conclusion: Health personnel are of the opinion that the aggressive behavior of the patients does not correspond to the situation they are in and there is no acceptable excuse for such behaviors.

Keywords: Health Personnel, Exposure to Violence, Aggression, Perception.

\section{INTRODUCTION}

According to the World Health Organization (WHO), violence is described as the use of threats or physical force that may result in physical damage, death, developmental disorders, and deprivation against oneself, another person, a community, and a group [1].

Workplace violence is an incident in which personnel is abused, threatened, or attacked in the circumstances associated with their job, including explicit or implicit threats to their commute, safety, wellbeing, or health. Violence is increasing rapidly in healthcare institutions due to reforms, high work pressure and stress, social instability, and deterioration of personal relationships. Growing domestic violence and the violence on the streets also cause violence in health institutions. Violence in the healthcare sector accounts for almost a quarter of violence in the workplace. Recent studies reveal that although there are local differences, violence in the health sector is universal and harms the health of both women and men, although some are at greater risk. Violence affects more than half of healthcare professionals [2].

Violence in healthcare institutions is described as "the situation that comes from the patient, patient

*Address correspondence to this author at the Yozgat Bozok University, Tıp Fakültesi Halk Sağlığı AD, E. Akdağ Kampüsü 66900-Yozgat, Turkey; Tel: +90(542) 773-6196; Fax: +90(354) 214-0612; E-mail: mahmutkilic@yahoo.com relatives or any other individual, that poses a risk to the healthcare worker, and consists of threatening behaviour, verbal threat, economic abuse, physical and sexual assault" [3]. Healthcare professionals are the most prominent targets and victims of workplace violence. $93 \%$ of all attacks against employees and $75 \%$ of severe attacks occur in hospitals. Studies have revealed that those working in the health sector are at risk of being exposed to violence 16 times more than those working in other sectors [4-6]. According to $\mathrm{WHO}$, healthcare workers are at risk of violence across the world. $8 \%$ to $38 \%$ of healthcare professionals are exposed to physical violence in their professional life. Again, the majority are threatened or verbally attacked. Patients and their relatives perpetrate most of the violence. Among healthcare professionals, those most at risk are nurses and other healthcare professionals such as emergency room personnel and paramedics who give direct patient care. Violence adversely affects not only the psychological and physical health of healthcare professionals but also their work motivation. Consequently, violence can undermine the quality of care and put healthcare provision at risk. Moreover, it causes significant financial losses in the health sector [7].

In a study conducted across Turkey in general, it has been observed that $44.7 \%$ of healthcare workers have been subjected to workplace violence in the last 12 months; $6.8 \%$ to physical violence and $43.2 \%$ to 
verbal violence [8]. Studies have revealed that more challenging circumstances such as injuries are perceived as violence, and very few other types of attacks are recorded. Hospitals are risky environments for healthcare professionals, so physicians and healthcare professionals do not feel safe. Both rapid changes in healthcare services and deficiencies in legal practices seem to be problem areas in preventing violence and ensuring employee safety $[2,9,10]$.

Sources of violence against healthcare professionals are colleagues, patients, patients' relatives, and visitors. The fact that especially the relatives of the patients believe that their patient is more critical than others and should be treated immediately and that the patients and their relatives think that the system is chaotic or that they are not treated fairly during the examination, and that healthcare professionals are more interested in patient's admission procedures are among the risk factors $[11,12]$.

While developing models for the prevention and management of aggression, health personnel's attitudes towards aggressive patients should be acknowledged. While assessing aggression, how the staff perceives and interprets the attitudes and behaviours of aggressive patients is a critical subject. For that purpose, several studies were conveyed to show the perception of aggression among nurses working in general hospitals and psychiatric hospitals. These studies centered on the causes and types of aggression, the characteristics of the perpetrators, the severity of the injury, the management of aggression, and the attitudes and opinions of nurses about aggression [13].

Aggression Perception Scale (APS) was developed to evaluate the attitudes of healthcare professionals towards patient aggression and/or violence. APS reveals the character of patient aggression and various aspects of healthcare personnel's attitude towards aggression. It also evaluates aggression as a normal functional reaction to the patient's condition and experience [14]. More evidence has emerged on the etiology and processes of aggression. Studies have revealed that besides the risk factors concerning patient aggression, changes in the mental state of the patient during their stay in the hospital are important [15].

The demographic characteristics of healthcare workers, the health institution and unit they work in, the outcomes of exposure to the attack of patients and their relatives on the perception of aggression being examined using multivariate analysis methods are the advantage of this study.

This study aims to evaluate the effect of the health personnel working in the provincial centre being exposed to the attack of patients and their relatives on the perception of aggression.

\section{MATERIALS AND METHODS}

\section{Research form}

This is a cross-sectional study.

\section{Research Universe and Sampling}

The research was carried in the Bozok University Research and Application Hospital, Yozgat State Hospital, and Family Health Centers (FHCs) in Yozgat's city center in April-May 2015. The population of the study consists of the healthcare personnel who worked in health institutions for at least one year and dealt with patients and their relatives. Sample selection was not made, and all health personnel were included in the study. The research was completed with 358 people who agreed to participate in the study by giving verbal consent. The power of the sample was calculated with the G-power program. When the effect size was $d=0.5, \alpha=0.05$, and exposure to violence group was $n=135$, the sample power (1- $\beta$ err prob) was calculated as 0.97 .

\section{Data Collection Tools}

The data of the study were obtained by a sociodemographic data form including the health personnel being attacked, and the Perception of Aggression Scale which was validated in Turkish by Bilgin et al. Data forms were filled in by healthcare personnel.

\section{Perceptions of Aggression Scale (POAS)}

The scale was developed as 32 items by Jansen et al. in 1997 [14]. As a result of the Turkish validity and reliability of the scale, 29 items were found appropriate. The answers to the questions are Likert type and scored as "strongly agree: 5, agree: 4, neutral: 3 , disagree: 2 , strongly disagree: 1". The scale has two sub-dimensions. Functional (acceptable-healthy reaction) consists of 12 items $(3,6,7,8,16,18,20,23$, $24,25,27,28)$ and 17 items if dysfunctional (unacceptable-unwanted aggression) $(1,2,4,5,9,10$, $11,12,13,14,15,17,19,21,22,26,29)$. Average 
sub-dimensions are obtained by dividing the score obtained from the sub-dimension by the number of items in that sub-dimension. High average scores refer to the high power of that sub-dimension. Higher functional sub-dimension score indicates that aggression is perceived as "functional/acceptable", higher dysfunctional sub-dimension score indicates that aggression is perceived as "dysfunctional/ unacceptable" [16]. The Turkish form of the scale was obtained from the author upon request to be used in the research.

\section{Statistical Analysis}

The data was analyzed in IBM SPSS Statistics Standard Concurrent User V 25, Authorization Code: e31d836848b0a60e5756. Chi-square, Student t-test, ANOVA, linear regression (LR), and binary logistic regression (BLR) analysis were used to investigate the data. Variables found significant at the $P<0.1$ level in univariate analyzes were included in the regression models. The stepwise model was used in LR, and the backward model was used in BLR, and the variables found significant are given in the table. Categorical variables were transformed into dummy variables for linear regression analysis and examined. The exposure to violence in the last 12 months was analyzed with BLR as the dependent variable. In the BLR analysis, first, the goodness of fit of the model was questioned by Hosmer and Lemeshow test, and the analysis was performed since $p>0.05[17,18]$.

\section{Ethical Consideration}

Written permission was obtained from the health institutions for the research. The healthcare personnel was informed about the purpose of the research, data collection forms, how the forms would be filled, and how long it would take, and they were completely free to participate in the study. People who verbally agreed to participate in the study were included. All procedures followed were in accordance with the ethical standards of the responsible committee on human experimentation (institutional and national) and with the Helsinki Declaration of 1975, as revised in 2013.

Ethics committee approval was taken from Bozok University Faculty of Medicine Non-Invasive Clinical Research Ethics Committee with the decision dated 25.05.2015 and numbered 25/09.

\section{Limitations}

Health personnel who worked in health institutions for at least one year were recruited. Since the research was conducted only among the health personnel working in the city centre of Yozgat, it does not include data concerning the employees in other places. Thus, research results cannot be generalized to other places and regions.

\section{RESULTS}

Sixty five point six percent of the participants in the study are women, $20.9 \%$ are physicians, $36.9 \%$ are nurses, $67.0 \%$ are married. The average age is $32.1 \pm$ 7.7 ; the average years of employment in the profession are $9.4 \pm 7.6$.

Eighty one point six percent of those participating in the study stated that they were subjected to violence by their patients or their relatives during their professional life and $37.7 \%$ in the last 12 months. The rate of experiencing violence was statistically different according to age groups and the health institution they work for $(p<0.05)$. Those working in the emergency department $(66.7 \%)$, the ones working in the public hospital $(48.3 \%)$, and the younger ones are exposed to more violence (Table 1).

According to the multivariate BLR analysis, the probability of being exposed to violence by patients and their relatives increases as the age gets younger. At the same time, it is 11.0 times higher for those working in the emergency department, 3.3 times for those working in the clinic, and 3.6 times higher for those working in other units compared to those working in FHCs. Those working in the emergency department are 3.3 times more prone to be exposed to violence than those working in the clinic $(p<0.05)$. The risk of exposure to violence for those working in the clinic and other units is at a comparable level. In terms of exposure to violence, profession, institution, duration of work, and marital status were not statistically significant $(p>0.05)$ (Table 2).

The functional (acceptable/comprehensible phenomenon) reaction items mean is $2.31 \pm 0.77$, and the dysfunctional (unacceptable/undesirable phenomenon) reaction items mean is $3.96 \pm 0.53$ (Table 3 ).

Functional aggression perception is higher in the 30-39 age group and graduate medical staff, while dysfunctional aggression perception is higher in emergency department workers $(p<0.05)$. According to the multivariate LR analysis, the perception of functional aggression was higher in those who work in university hospitals, while it was lower in physicians $(p<0.05)$. Age, education level, duration of work 
Table 1: Exposure to Violence in the Last 12 Months by Demographic Characteristics

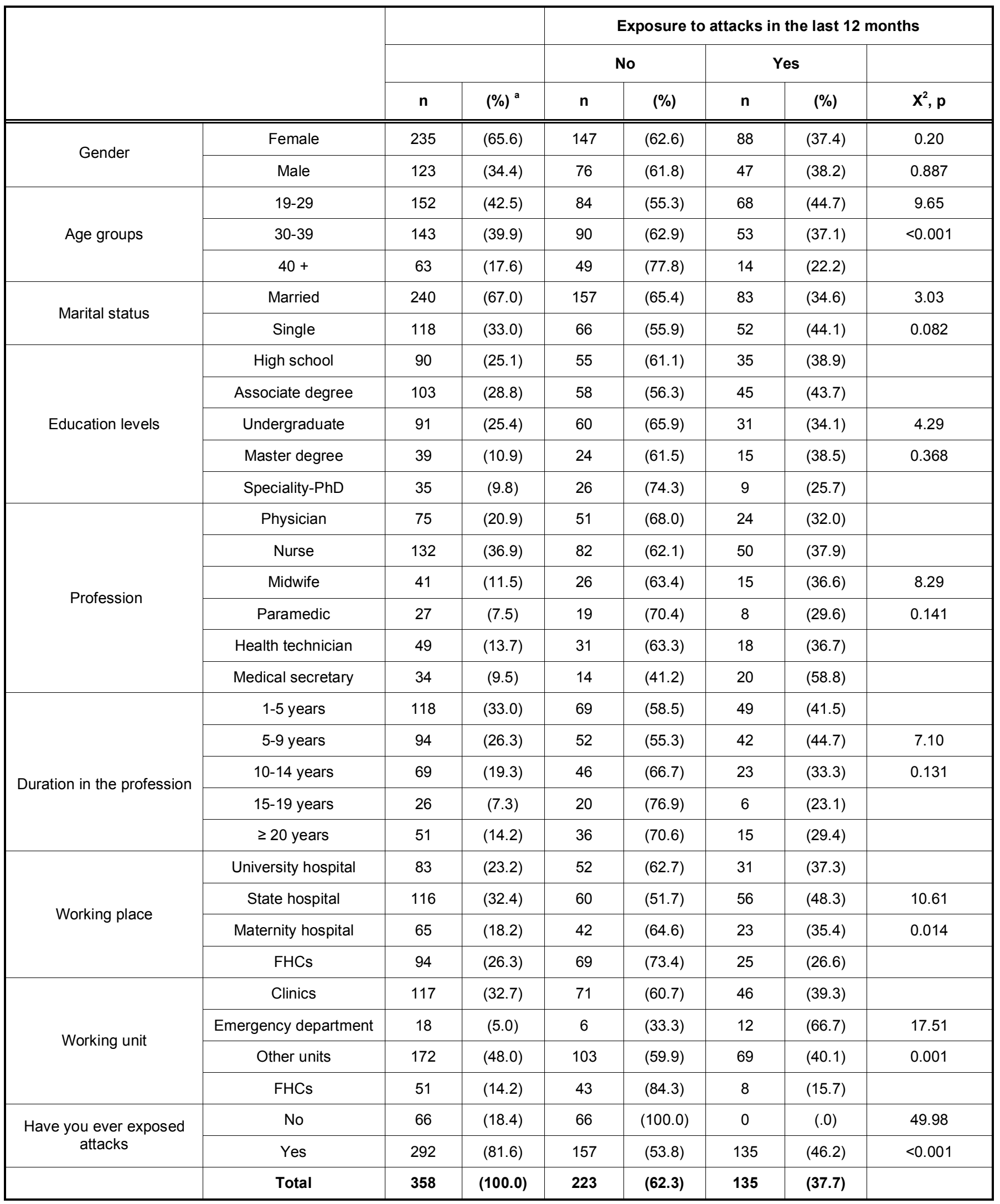

${ }^{a}$ Percentages are based on the column total. FHC: Family Health Center. 
Table 2: Analysis of Exposure to Violence in the Last 12 Months Using Multivariate Binary Logistic Regression

\begin{tabular}{|c|c|c|c|c|c|}
\hline & \multirow[b]{2}{*}{$\mathbf{B}$} & \multirow[b]{2}{*}{$\mathbf{P}$} & \multirow[b]{2}{*}{ Odds Ratio } & \multicolumn{2}{|c|}{$95 \%$ Confidence Interval } \\
\hline & & & & Lower bound & Upper bound \\
\hline Age & -0.032 & 0.032 & 0.968 & 0.940 & 0.997 \\
\hline Working unit $(\mathrm{FHC}=1)$ & & 0.001 & & & \\
\hline Clinics & 1.215 & 0.005 & 3.370 & 1.448 & 7.843 \\
\hline Emergency department & 2.403 & $<0.001$ & 11.051 & 3.177 & 38.436 \\
\hline Other units & 1.302 & 0.002 & 3.675 & 1.621 & 8.332 \\
\hline Constant & -0.648 & 0.288 & 0.523 & & \\
\hline
\end{tabular}

Independent variables: Age, marital status, profession, duration in the profession (year), working place, working unit. FHC: Family Health Center.

Table 3: Distribution of the Mean of POAS Sub-Dimensions According to Demographic Characteristics

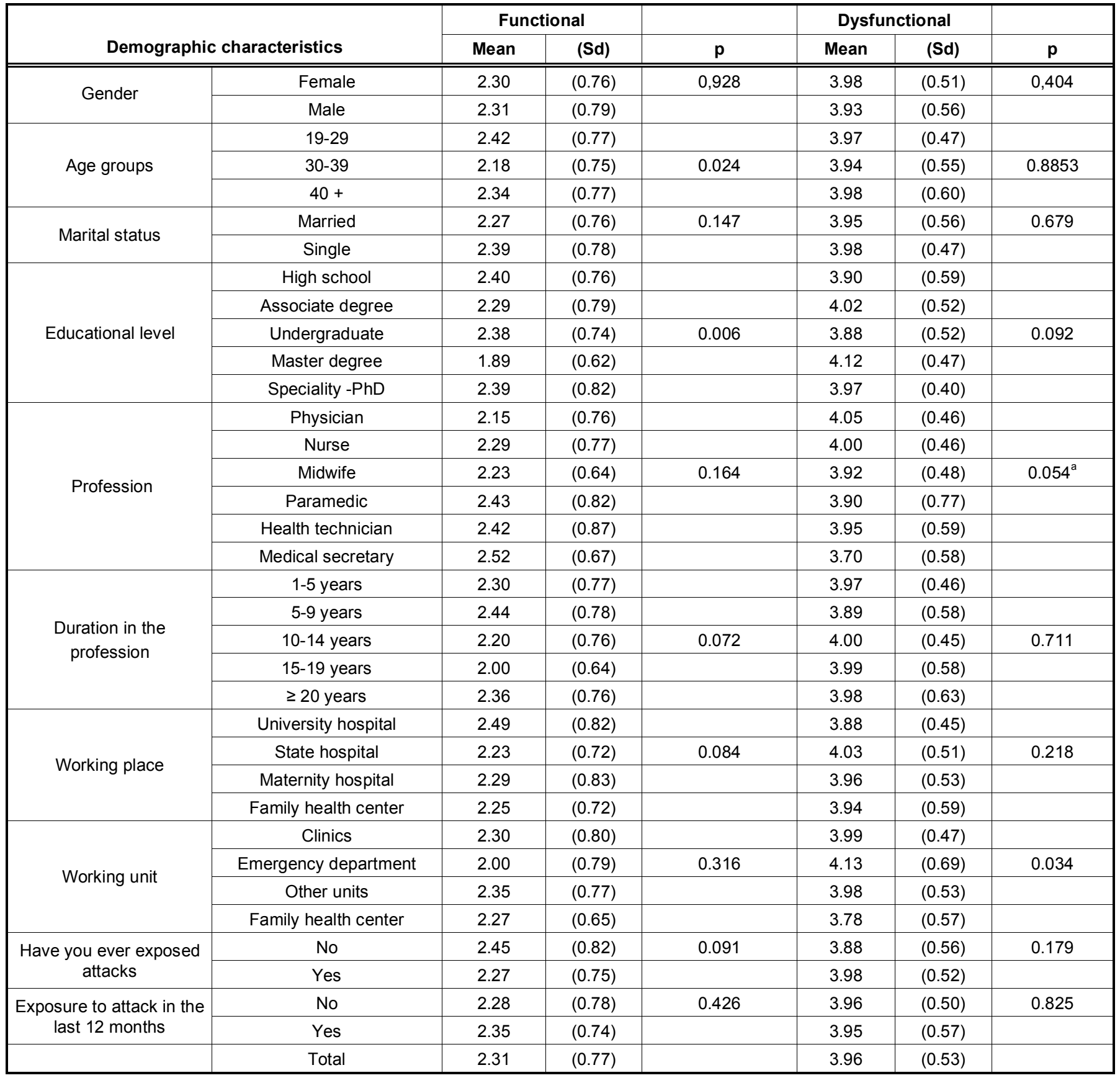

${ }^{a}$ Kruskal-Wallis tests. POAS: Perceptions of Aggression Scale. Sd: Standard deviation. 
Table 4: Analysis of Variables that may be Associated with the Sub-Dimensions of Aggression Perception by Linear Regression

\begin{tabular}{|c|c|c|c|c|c|c|c|}
\hline \multirow[b]{2}{*}{ Functional $^{\mathrm{a}}$} & \multicolumn{2}{|c|}{$\begin{array}{l}\text { Unstandardized } \\
\text { Coefficients }\end{array}$} & \multirow{2}{*}{$\begin{array}{c}\begin{array}{c}\text { Standardized } \\
\text { Coefficients }\end{array} \\
\text { Beta }\end{array}$} & \multirow[b]{2}{*}{$\mathbf{t}$} & \multirow[b]{2}{*}{$\mathbf{p}$} & \multicolumn{2}{|c|}{ B 95\% Confidence Interval } \\
\hline & B & Std. Error & & & & Lower bound & Upper bound \\
\hline Work place $=$ University hospital & 0.261 & 0.095 & 0.144 & 2.738 & 0.006 & 0.073 & 0.448 \\
\hline Profession=Physician & -0.220 & 0.099 & -0.117 & -2.227 & 0.027 & -0.414 & -0.026 \\
\hline (Constant) & 4.063 & 0.035 & & 114.577 & 0.000 & 3.994 & 4.133 \\
\hline Profession= Medical secretary & -0.318 & 0.093 & -0.177 & -3.408 & 0.001 & -0.502 & -0.135 \\
\hline $\begin{array}{l}\text { Working unit= Family health } \\
\text { center }\end{array}$ & -0.288 & 0.080 & -0.191 & -3.600 & 0.000 & -0.446 & -0.131 \\
\hline Work place $=$ University hospital & -0.140 & 0.066 & -0.112 & -2.119 & 0.035 & -0.270 & -0.010 \\
\hline
\end{tabular}

Independent variables: Age, education level, profession, duration in the profession (year), working place, Have you ever exposed attacks.

Independent variables: Education level, profession, working place, working unit.

(years), exposure to violence during the profession were not statistically significant in functional aggression $(p>0.05)$. The perception of dysfunctional aggression was lower in medical secretaries, those working at FHCs, and those working at university hospitals, and while this was statistically significant $(p<0.05)$, educational level was not significant $(p>0.05)$ (Table 4).

According to the statistical analysis results, no significant relationship was found between the perception of both functional (acceptable) and dysfunctional (unacceptable) aggression with age, gender, marital status, educational level, duration of employment (years), exposure to attack during professional life and in the last 12 months $(p>0.05)$ (Tables 3-4).

Of those who stated that they were assaulted (135), $53.9 \%$ were attacked by patients; $56.5 \%$ by the patients' relatives, $77.8 \%$ were verbally attacked, $80.7 \%$ were attacked by males, $37.0 \%$ were attacked when alone, $39.3 \%$ of them stated that they had expected to be attacked, $57.0 \%$ of them defended themselves during the attack. After the attack, 37.0\% stated that they reported the situation to their superiors, $18.5 \%$ informed the police-judicial authorities, and $90.4 \%$ stated that the measures taken against attacks were insufficient (Table 4).

\section{DISCUSSION}

In this study, the effect of healthcare personnel's exposure to the attack of patients and their relatives on the perception of aggression was examined. The health personnel's exposure to violence, the types and reasons of violence are not the focus of this study. In the literature, it is observed that the studies on the perception of aggression are generally among nurses and psychiatric services. The level of aggression perception of healthcare personnel working in other units and professions has not been investigated much.

The vast majority $(81.6 \%)$ of the healthcare professionals participating in the study had been under attack in the workplace during their professional career and $37.7 \%$ in the last 12 months. According to multivariate analysis, younger people, as expected, working in the emergency department, are 3.3 times more likely to be exposed to violence than those working in the clinic and 11 times more than those working in the FHCs (Tables 1-2). In a study conducted in Turkey, the percentage of healthcare workers who encountered workplace violence in the last 12 months was $39.5 \%$ for men and $48.2 \%$ for women, and $44.7 \%$ in total. Again, in this study, being younger and working in the emergency department was riskier in exposure to violence [8]. In a study conducted in England, it was observed that $38 \%$ of healthcare workers and $45 \%$ in Italy were exposed to violence in the last 12 months $[19,20]$. In a study carried in the United States of America (USA) in $2014,39 \%$ of the nurses were exposed to verbal and $13 \%$ physical assault in the last 12 months. It is $75 \%$ verbal and $21 \%$ physical in emergency department physicians and $100 \%$ and $82.1 \%$ for nurses [6]. In a retrospective study (2014) it was observed that $68 \%$ of the emergency service personnel thought they were not safe at work, $88 \%$ were exposed to verbal violence at work, $80 \%$ were exposed to physical violence, but only $49 \%$ reported 
the incident to the police [21]. In a study conducted in Istanbul, it was discovered that $63.2 \%$ of those subjected to violence from healthcare personnel were women, $71.9 \%$ were doctors, and $20.9 \%$ were nurses, according to the code white report. When examined on a unit basis, it was seen that $42.1 \%$ were in the emergency service and $26.7 \%$ in the inpatient services [22]. The findings of this study are similar to the other literature findings in our country.

Due to this study, $59.3 \%$ of the healthcare workers reported the situation, $37.0 \%$ to their superiors, $18.5 \%$ to the police-judicial authorities after the attack (Table 4). Studies reveal that most of the healthcare workers do not report their situation. It was determined that among the reasons for not making a complaint, there was distrust in the health and managing directors and the justice mechanism $[23,24]$. In a study conducted in Italy, it was found that $84 \%$ of them did not report the attack they were exposed to [20]. There are differences in terms of reporting in some studies conducted in our country and other countries. It is thought that the said persons do not complain because they think that they will not get any result due to the institutional policies regarding violence in health institutions in our country.

POAS functional reaction (healthy reaction) items mean (2.31), which tries to measure how healthcare professionals perceive the patients' aggressive behaviour, is lower than the scale items mean (2.50) as expected. The dysfunctional reaction (undesired/unhealthy reaction) items mean is (3.96). It was much higher than the average (2.50) (Table 3). According to multi variables regression analysis, while the perception of functional aggression was higher in university hospital's staff, it was lower in physicians. The perception of dysfunctional aggression was lower in medical secretaries, those working at FHCs, and those working at university hospitals (Table 4). In a study conducted among nurses in the emergency department in Samsun, the average perception of dysfunctional aggression (4.01) was similar to our findings. In contrast, the average functional aggression perception (1.97) was lower than our findings, as expected, due to emergency service workers [25]. In a study conducted in psychiatry wards in Turkey, the mean score of nurses' perceptions of functional aggression (2.95) was higher than our findings. In contrast, the mean score for dysfunctional (3.38) was lower [26]. Patients hospitalized in the Emergency Psychiatry ward usually demonstrate aggressive behaviour. It may be because the study was conducted in the psychiatry service. In a study carried among healthcare professionals in psychiatric hospitals in Poland and Norway, the average positive and negative aggression scores were identified as 3.13 and 2.93 in Norway and 2.63 and 3.73 in Poland, respectively [27]. Our study findings are similar to the data of Poland.

There was no significant relationship between the perception of both functional (acceptable) and dysfunctional (unacceptable) aggression and the healthcare personnel's age, gender, marital status, educational status, duration of work (years), professional career, and exposure to attack in the last 12 months $(p>0.05)$ (Tables 3-4). In a study carried out in Switzerland, no relationship was found between nurses' exposure to violence and their perception of aggression [28]. Functional aggression perception was higher in university hospitals and lower in physicians $(p<0.05)$. The perception of dysfunctional aggression was lower in medical secretaries, those working in FHCs, and those working in university hospitals $(p<0.05)$ (Table 4). In a study, it was discovered that nurses with more professional experience and men were more prone to see patient aggression as dysfunctional (undesirable), and younger nurses were more likely to see aggression as functional (desired) [29]. These factors were not significant in our study. In a study among nurse administrators covering three countries, the aggression of patients and their relatives did not differ significantly according to countries or levels of administration. Most of the administrators perceived the aggression of patients and their relatives neither negatively nor positively, but administrators working in mental health services perceived aggression as a positive force [30]. It may seem normal that executive nurses have neither positive nor negative attitudes concerning aggression since they are generally not directly attacked by patients and their relatives. Still, having this kind of attitude by managers may prevent them from making sufficient effort to prevent aggression towards staff. In our study, $90.4 \%$ of the healthcare personnel recognize the measures taken as insufficient displays how serious the attitudes of the managers on aggression are.

\section{CONCLUSION}

In this study, no significant relationship was discovered among the perception of functional and dysfunctional aggression of healthcare professionals and their previous exposure to attack by patients and their relatives.

Healthcare personnel believe that the patients' aggressive behaviour is not an appropriate response to 
their situation and that such behaviour cannot have a satisfactory excuse.

It is considered that legal regulations, raising awareness of the society, providing training for healthcare professionals, and being more sensitive to the issue to protect healthcare professionals from the attacks of patients and their relatives will contribute experiencing the difficulty at a minimum level.

\section{ACKNOWLEDGEMENT}

The summary data of this study were presented as verbal presentations at the 19th National Public Health Congress, Antalya on 15-19 March 2017.

\section{CONFLICTS OF INTEREST}

We wish to confirm that there are no known conflicts of interest associated with this publication and there has been no significant financial support for this work that could have influenced its outcome.

\section{INFORMED CONSENT}

Informed consent was obtained from all patients for being included in the study.

\section{REFERENCES}

[1] WHO. World Report on Violence and Health [Internet] 2002. Available from: https://apps.who.int/iris/bitstream/10665/ 42495/1/9241545615 eng.pdf

[2] ILO, WHO. Framework guidelines for addressing workplace violence in the health sector [Internet]. International Labour Office. Geneva, Switzerland; 2002. Available from: https://www.who.int/violence_injury_prevention/violence/inter personal/en/WVguidelinesEN.pdf?ua=1\&ua=1

[3] Saines JC. Violence and aggression in A\&E: recommendations for action. Accid Emerg Nurs. Elsevier; 1999; 7(1): 8-12.

https://doi.org/10.1016/S0965-2302(99)80094-0

[4] Elliott PP. Violence in health care. Nurs Manage. Lippincott Williams \& Wilkins Ovid Technologies 1997; 28(12): 38 https://doi.org/10.1097/00006247-199712000-00012

[5] Cooper C, Swanson N. Workplace violence in the health sector. State art Geneva Organ Int Trab Organ Mund la Salud, Cons Int Enfermeras Int Serv Públicos 2002.

[6] Phillips JP. Workplace violence against health care workers in the United States. N Engl J Med. Mass Medical Soc 2016; 374(17): 1661-9.

https://doi.org/10.1056/NEJMra1501998

[7] WHO. Violence against health workers [Internet]. Violence and Injury Prevention 2020 [cited 2020 May 15]. Available from: https://www.who.int/violence_injury_prevention/ violence/workplace/en/

[8] Pinar T, Acikel C, Pinar G, Karabulut E, Saygun M, Bariskin $\mathrm{E}$, et al. Workplace violence in the health sector in Turkey: a national study. J Interpers Violence. SAGE Publications Sage CA: Los Angeles, CA; 2017; 32(15): 2345-65. https://doi.org/10.1177/0886260515591976
[9] Ünsal Atan S, Dönmez S. Hemşirelere karşı işyeri şiddeti. Adli Tıp Derg 2011; 25(1): 71-80.

[10] Annagür B. Sağlık çalışanlarına yönelik şiddet: risk faktörleri, etkileri, değerlendirilmesi ve önlenmesi. Psikiyatr Güncel Yaklaşımmlar 2010; 2(2): 161-73.

[11] Serin H, Serin S, Bakacak M, Ölmez S. Sağlık çalışanlarına yönelik şiddet. Sürekli Tıp Eğitimi Derg 2015; 24(3): 109-13.

[12] Solmaz B, Duğan Ö. Sağlık çalışanı ile hasta ve yakınları arasında yaşanan şiddetin nedenlerinden "iletişim" üzerine bir inceleme. Bolu Abant $\{\backslash \mid\} z z e t$ Baysal Üniversitesi Sos Bilim Enstitüsü Derg 2018; 18(2): 185-206. https://doi.org/10.11616/asbed.v18i38801.459750

Jansen GJ, Dassen TWN, Groot Jebbink G. Staff attitudes towards aggression in health care: a review of the literature. J Psychiatr Ment Health Nurs. Wiley Online Library; 2005; 12(1): 3-13. https://doi.org/10.1111/j.1365-2850.2004.00772.x

[14] Jansen G, Dassen T, Moorer $P$. The perception of aggression. Scand J Caring Sci. Wiley Online Library; 1997; 11(1): 51-5.

https://doi.org/10.1111/j.1471-6712.1997.tb00430.x

[15] Almvik R, Woods P, Rasmussen K. The Brøset Violence Checklist: sensitivity, specificity, and interrater reliability. $J$ Interpers Violence. Sage Publications, Inc.; 2000; 15(12): 1284-96. https://doi.org/10.1177/088626000015012003

[16] Bilgin H, Tulek Z, Ozcan N. Psychometric properties of the Turkish version of the Perception of Aggression Scale. J Psychiatr Ment Health Nurs. Wiley Online Library; 2011; 18(10): 878-83. https://doi.org/10.1111/j.1365-2850.2011.01742.x

[17] Kalaycı Ş. Uygulamalı Çok Değişkenli İstatistik Teknikleri. Ankara: Asil Yayın Dağıtım; 2006.

[18] Meyers LS, Gamst G, Guarino AJ. Applied multivariate research: Design and interpretation. London: Sage publications; 2006.

[19] Quine L. Workplace bullying in NHS community trust: staff questionnaire survey. Bmj. British Medical Journal Publishing Group; 1999; 318(7178): 228-32. https://doi.org/10.1136/bmj.318.7178.228

[20] Ferri P, Silvestri M, Artoni C, Di Lorenzo R. Workplace violence in different settings and among various health professionals in an Italian general hospital: a cross-sectional study. Psychol Res Behav Manag. Dove Press; 2016; 9: 263. https://doi.org/10.2147/PRBM.S114870

[21] Furin M, Eliseo LJ, Langlois B, Fernandez WG, Mitchell $P$, Dyer KS. Self-reported provider safety in an urban emergency medical system. West J Emerg Med. California Chapter of the American Academy of Emergency Medicine (Cal/AAEM); 2015; 16(3): 459. https://doi.org/10.5811/westjem.2015.2.24124

[22] Polat Ö, Çırak M. Sağlıkta şiddetin Beyaz Kod verileri ile değerlendirilmesi 2019;

[23] Aydın M. Isparta-burdur sağlık çalışanlarına yönelik şiddet ve şiddet algısı. Türk Tabipleri Birliği, Isparta-Burdur Tabip Odası Başkanlığı 2008; 1-34.

[24] Yıldız MS. Türkiye'de sağıık çalışanlarına yönelik şiddet: Ankara ilinde araştırma. Hacettepe Sağlık İdaresi Derg 2019; 22(1): 135-56.

[25] Kıymaz D, Mıdık Ö. Determining the relationship between communication skills of nurses working in emergency service and their aggression perception and exposure to violence. ASOS J [Internet] 2020; 8(101): 419-37. Available from: http://www.asosjournal.com/files/asosjournalmakaleler/6b10ff b1-de7f-4141-a088-80b61073eaa9.pdf

[26] Keser Özcan N, Bilgin H, Akın M, Badırgalı Boyacıoğlu NE. Nurses' attitudes towards professional containment methods used in psychiatric wards and perceptions of aggression in 
Turkey. J Clin Nurs. Wiley Online Library; 2015; 24(19-20): 2881-9.

https://doi.org/10.1111/jocn.12903

[27] Lickiewicz J, Nag T, Ravnanger C, Jagielski Pawełand Makara-Studzińska M. The Perception of aggression towards the medical personnel of psychiatric wards in Poland and in Norway--a comparative analysis. Arch Psychiatry Psychother 2019; 3: 61-70. https://doi.org/10.12740/APP/110698

[28] Hahn S, Müller M, Needham I, Dassen T, Kok G, Halfens RJG. Factors associated with patient and visitor violence experienced by nurses in general hospitals in Switzerland: a cross-sectional survey. J Clin Nurs. Wiley Online Library; 2010; 19(23-24): 3535-46.

https://doi.org/10.1111/j.1365-2702.2010.03361.x

[29] Palmstierna T, Barredal E. Evaluation of the Perception of Aggression Scale (POAS) in Swedish nurses. Nord J Psychiatry. Taylor \& Francis; 2006; 60(6): 447-51. https://doi.org/10.1080/08039480601021803

[30] Heckemann B. The Manager's Perspective: Perceptions of and Behaviors Toward Patient and Visitor Aggression in Hospitals (PERoPA). An international online survey 2017.

Received on 07-09-2020

Accepted on 13-10-2020

Published on $26-10-2020$

https://doi.org/10.6000/1929-6029.2020.09.06

(C) 2020 Mahmut Kilic; Licensee Lifescience Global.

This is an open access article licensed under the terms of the Creative Commons Attribution Non-Commercial License (http://creativecommons.org/licenses/by-nc/3.0/) which permits unrestricted, non-commercial use, distribution and reproduction in any medium, provided the work is properly cited. 